\title{
An ecological analysis of pertussis disease in Minnesota, 2009-2013
}

\author{
P. Y. IROH TAM ${ }^{1 *}$, J. S. MENK ${ }^{2}$, J. HUGHES $^{3}$ AND S. L. KULASINGAM ${ }^{3}$ \\ ${ }^{1}$ University of Minnesota Masonic Children's Hospital, Minneapolis, MN, USA \\ ${ }^{2}$ Clinical and Translational Science Institute, University of Minnesota, Minneapolis, MN, USA \\ ${ }^{3}$ University of Minnesota School of Public Health, Minneapolis, MN, USA
}

Received 23 March 2015; Final revision 17 July 2015; Accepted 13 August 2015; first published online 2 September 2015

\section{SUMMARY}

The increase in pertussis cases in Minnesota in the last decade has been mainly attributed to the switch from whole cell to acellular pertussis [as part of the diphtheria, tetanus and acellular pertussis vaccine (DTaP)]. It is unclear, however, to what degree community-level risk factors also contribute. Understanding these factors can help inform public health policy-makers about where else to target resources. We performed an ecological analysis within Minnesota to identify risk factors at the county level using a Bayesian Poisson generalized linear areal model to account for spatial dependence. Univariate analyses suggested an association between increased pertussis rates at the county level and white maternal ethnicity, being US born, urban counties and average household size. In the multivariable analysis, the rate of pertussis was 1.79 times greater for urban $v s$. rural counties and 4.75 times greater for counties with a one-person larger average household size. Pertussis rates in counties with higher (i.e. 4+DTaP) receipt in children were 0.97 times lower. Examining county-level factors associated with varying levels of pertussis may help identify those counties that would most benefit from targeted interventions and increased resource allocation.

Key words: Bordetella pertussis, pertussis (whooping cough), respiratory infections, spatial modelling, vaccine-preventable diseases.

\section{INTRODUCTION}

The United States has seen a surge in reported pertussis cases over the past decade [1, 2]. In 2012 the largest outbreak of pertussis in 50 years occurred, with over 41000 reported cases nationally [3]. That year, Minnesota had the third highest incidence of pertussis of any state in the nation, with 4144 cases of pertussis reported, equivalent to $75 / 100000$ population [3].

\footnotetext{
* Author for correspondence: Dr P. Y. Iroh Tam, 3-210 MTRF, 20016 th St SE, Minneapolis, MN 55455, USA.

(Email: irohtam@umn.edu)
}

Rates this high had not been reported for the state since 1938 [4].

Reasons for the resurgence have centred around the diphtheria, tetanus, and acellular pertussis (DTaP) vaccine: particularly under-immunization $[5,6]$, parental refusal of vaccination $[7,8]$, and waning immunity provided by the acellular pertussis formulation $[9,10]$. Efforts to protect infants, the group with the highest risk of death or serious morbidity, have focused on 'cocooning' the infant by immunizing the surrounding caregiver group [11-13], as well as by immunizing peripartum women [14, 15]. However, less attention has been directed at determining environmental and social 
factors that may also contribute to the increased rates of pertussis.

Ecological analyses can be used to identify associations between aggregate demographic factors and disease [16], as well as improve our understanding of varying pertussis rates, transmission dynamics, immunity, and vaccine effectiveness [17]. Ecological analyses have been conducted to examine the effect of pertussis vaccine coverage on county-level pertussis incidence rates in California during the 2010 pertussis epidemic [18]. However, few have used an ecological approach to identify demographic and socioeconomic variables associated with higher county-level pertussis rates within a state. The objective of our study was to describe the geographical distribution of pertussis rates in Minnesota, and to identify county-level public health, education, economic and demographic indicators that are associated with increased county-specific pertussis rates.

\section{METHODS}

\section{Data collection}

County-level data were collected for 61 variables, including 20 demographic, 17 education, 14 health, seven socioeconomic, and three vaccination status indicators from various data sources (see Appendix). Sources included the US Census [19], the Minnesota Department of Health (MDH) [20], the Minnesota Board of Medical Practice (M. Chu, written communication), the Minnesota Geospatial Information Office [21], and the National Center for Health Statistics [22]. Data used in this analysis ranged from estimates for individual years, to those based on a 5-year span (2009-2013), in order to yield estimates for all 87 counties within Minnesota. Separate sources for different county-level variables were combined into a single dataset for analysis, based on US Census data that showed that the population was fairly static over the 5-year period [19]. Data used in this analysis were assumed to provide a reasonable estimate of the population values for 2009 to 2013. In particular, when data for a given variable were available for a single year (e.g. 2011), we assumed it was representative of the other years (e.g. 2009, 2010, 2012, and 2013).

County-specific explanatory variables were collected or computed as percentages by county to account for population size. If an explanatory variable was available only for one year, this value was used and assumed representative of the 5-year period.
Five-year data were available as a 5-year median, 5 -year average, or 5-year percentages where the median, average or percentage was computed using the cumulative data over 5 years.

\section{Variables examined}

Pertussis cases were obtained from the MDH [20] at the county-level and encompassed all ages, and included patients who met the case definition of pertussis: clinical symptoms with paroxysms of coughing, inspiratory whoop, or post-tussive vomiting, or apnoea in infants aged $<1$ year; laboratory isolation of Bordetella pertussis from a clinical specimen, or positive PCR for $B$. pertussis; and contact with a laboratory-confirmed case of pertussis. County-level demographic indicators examined included the following: population density, average household size, natural rate of population increase, number of schools, and urban/rural designation as proxies for crowding. Urban and rural designation followed the National Center for Health Statistics classification [22]. Urban areas included large central/large fringe metropolitan (populations of $\geqslant 1$ million) to small metropolitan (populations $<250000$ ). Rural, non-metropolitan areas included micropolitan (containing at least one urban cluster of 10000-49999 inhabitants) and non-core (most rural area) [22].

Socioeconomic indicators included median income, employment, medical insurance, enrolment in medical assistance programmes, as well as educational attainment, maternal educational attainment, single-parent households, English only spoken at home, teen birth rates, and births to unmarried mothers. Asthma hospitalization was also considered a socioeconomic indicator, based on documented disparities in asthma management and self-efficacy by race, ethnicity and income [23]. Age data were for $0-4,5-9,10-19$, and $\geqslant 65$ years age groups.

Children aged $<5$ years were noted to have completed the vaccine series if they had received the recommended DTaP vaccine series by age 35 months which, if the routine immunization schedule is followed, means receipt of four doses of DTaP by 18 months. Vaccine exemption rates were not publicly available at the county level. Varicella vaccination was used as a proxy for vaccine exemption, given previous literature that showed that this was the most common vaccine exempted [24]. We also included adult and childhood obesity, based on studies of a possible link between infection and obesity [25]. 


\section{Statistical analysis}

We applied the sparse spatial generalized linear mixed model (SGLMM) of Hughes \& Haran [26]. The sparse SGLMM allowed us to account for spatial dependence and spatial confounding in the counties. Spatial dependence is defined as counties that are in close proximity having similar outcomes. Spatial confounding is a type of redundancy for one or more risk factors [27]. Failure to account for spatial dependence can result in confidence intervals that are too narrow, while failure to address spatial confounding can result in confidence intervals that are too wide. By using the SGLMM we address the former, which reduces the possibility of concluding that unimportant factors are in fact important, while addressing the latter, reducing the possibility of concluding that important factors are unimportant. Further, we employed the sparse SGLMM for (conditionally independent) Poisson outcomes. This model assumes that the outcomes are independent and Poisson distributed, conditional on a collection of spatially dependent random effects, where there is exactly one random effect for each areal unit (in this case, each county).

The raw incidence rate of pertussis was calculated per 10000 person-years using the 2011 population with the assumption that the population is stable over the 5 years and that the mid-point population is the same population at risk for the entire 5 years. For the univariate and multivariable analysis, the response variable was the total number of cases reported for the county over the 5-year period; the 2011 county population was included as an offset. This also reduced zero counts for some counties in individual years. Bonferroni-corrected credible intervals were computed for the 67 separate comparisons, to maintain an overall significance level of 0.05 for all of the intervals (with an associated credible interval of $99.9 \%$ ). This reduces the chance of concluding there is a true association, when there is in fact no association. The Bonferroni correction is conservative, i.e. we are less likely to make an incorrect conclusion compared to alternative methods for multiple comparison adjustment at the cost of reduced power for detecting a real effect. Univariate analyses were used to identify variables for inclusion in the multivariable analysis based on statistical significance and included urban/rural designation, maternal educational attainment, percentage of children who received $\geqslant 4$ doses of DTaP, health insurance, number of family physicians and paediatricians per 100000 persons, and size of household. Commonly considered confounders such as race/ethnicity were also controlled for in the multivariable analysis, by being included in the model as a percentage of each group. Data were analysed with $\mathrm{R}$ software version 3.0.3 (R Foundation for Statistical Computing, Austria); the R package used to perform the SGLMM was 'ngspatial' [28].

This study used de-identified publically available data and was considered exempt by the University of Minnesota Institutional Review Board.

\section{RESULTS}

Between 2009 and 2013 there were 8117 cases of pertussis reported in Minnesota. The incidence rate per 10000 person-years ranged from 0 in Lincoln County, to 9.52 in Benton County (Fig. 1). The five counties with highest pertussis incidence rates were Benton, Wright, Sibley, Stearns, and Freeborn, and the five with the lowest pertussis incidence rates were Lincoln, Pennington, Becker, Martin and Le Sueur (Table 1).

Table 2 summarizes the results of the univariate analyses. Fourteen factors were associated with an increase in pertussis incidence, including younger age, population density, natural rate of increase in the population, white maternal race, US born, English only spoken at home, high maternal education, median income and proportion in labour force, among others. Two factors were associated with a substantial increase in pertussis rates: (1) urban-designated counties had a pertussis rate 2.32 times higher than rural-designated counties, and (2) a 1-unit increase in average household size was associated with a pertussis rate 2.62 times higher.

Factors associated with a decrease in pertussis incidence included older age, foreign born, language other than English spoken at home, lower educational attainment and lower maternal educational attainment, uninsured and single-parent households, among others (Table 2). Of the sociodemographic factors associated with a decrease in pertussis incidence, there were two notable associations: a 1-unit increase in the number of family physicians per 100000 was associated with a pertussis incidence 100 times lower, and a 1-unit increase in the density of schools in a county (school per 1000 persons) was associated with a pertussis incidence that was 1.32 times lower. A similar association was noted at each school level, where a 1-unit increase in density of elementary schools per 1000 persons was associated with a 


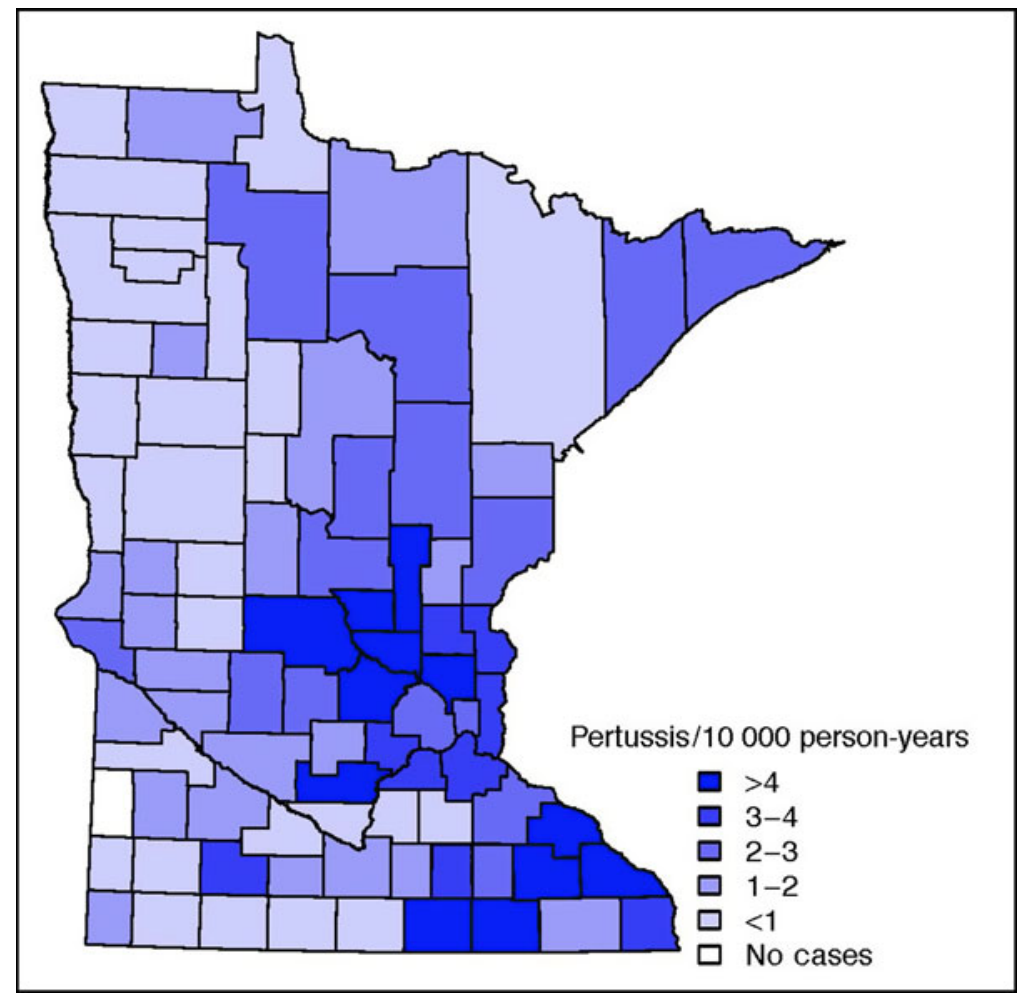

Fig. 1. Map of pertussis county-level incidence rates per 10000 person-years in Minnesota, 2009-2013.

Table 1. The five Minnesota counties with the lowest and highest pertussis incidence rates per 10000 person-years, 2009-2013

\begin{tabular}{lclr}
\hline \hline \multicolumn{2}{l}{$\begin{array}{l}\text { Counties with the lowest } \\
\text { pertussis incidence rate }\end{array}$} & \multicolumn{2}{l}{$\begin{array}{l}\text { Counties with the highest } \\
\text { pertussis incidence rate }\end{array}$} \\
\hline Lincoln & $0 \cdot 00$ & Benton & $9 \cdot 52$ \\
Pennington & $0 \cdot 14$ & Wright & $7 \cdot 18$ \\
Becker & $0 \cdot 18$ & Sibley & $7 \cdot 12$ \\
Martin & $0 \cdot 19$ & Stearns & $7 \cdot 06$ \\
Le Sueur & $0 \cdot 22$ & Freeborn & $6 \cdot 48$ \\
\hline \hline
\end{tabular}

pertussis incidence that was 2.32 times lower; an incidence rate that was 1.59 times lower for each middle school added per 1000 persons; and an incidence rate that was 3.28 times lower for each high school added per 1000 persons. No significant association was found between pertussis counts and the number of pediatricians per 100000 , but the point estimates were similar to that of family physicians.

In the multivariable analysis (Table 3), urban county designation (compared to rural county) remained significant and larger average household size was also associated with higher pertussis rates, with rate ratios of $1.79[99 \cdot 9 \%$ credible interval $(\mathrm{CrI})$
$1 \cdot 43-2 \cdot 31]$ and $4.75(99.9 \%$ CrI $1 \cdot 10-23 \cdot 97)$, respectively. Counties with higher rates of 4+ DTaP vaccine receipt in children aged 24-35 months were associated with lower incidence rates of pertussis, with a rate ratio of $0.97(99.9 \% \mathrm{CrI} 0.96-0.99)$ for a $1 \%$ higher prevalence of $4+\mathrm{DTaP}$ vaccine receipt.

Although an association was noted in the univariate analysis between county maternal education level and the pertussis incidence rate, in the multivariable analysis these associations were no longer significant.

\section{DISCUSSION}

In this ecological analysis, we identified several demographic and social factors potentially associated with varying incidence rates of pertussis in Minnesota. Of note, higher pertussis rates were associated with urban county designation and counties with larger average household size. Lower pertussis rates were significantly associated with receipt of the DTaP vaccine series, where counties with a $1 \%$ higher percentage of children aged 24-35 months who received 4+ DTaP had 0.97 times the incidence rate of pertussis. This finding is in keeping with other studies that show that unvaccinated or under-vaccinated children are at high risk for pertussis and increase the 
Table 2. Univariate regression analysis of the relationship between demographic and social indicators and pertussis incidence rate

\begin{tabular}{|c|c|}
\hline Indicator & $\operatorname{RR}(99 \cdot 9 \% \mathrm{CrI})^{*}$ \\
\hline \multicolumn{2}{|l|}{ Age $(\%)$} \\
\hline $0-4$ years & $1 \cdot 19(1 \cdot 09-1 \cdot 31)$ \\
\hline $0-19$ years & $1 \cdot 06(1 \cdot 03-1 \cdot 11)$ \\
\hline$\geqslant 65$ years & $0.95(0.90-0.97)$ \\
\hline \multicolumn{2}{|l|}{ Race/ethnicity (\%) } \\
\hline White & $1 \cdot 02(0 \cdot 98-1 \cdot 04)$ \\
\hline Black & $1.00(0.97-1.02)$ \\
\hline Native American & $1.00(0.96-1 \cdot 03)$ \\
\hline Asian & $1.00(0.97-1.03)$ \\
\hline Hispanic & $0.99(0.96-1.02)$ \\
\hline \multicolumn{2}{|l|}{ Demographics } \\
\hline Population density & $1 \cdot 0004(1 \cdot 0002-1 \cdot 0005) \dagger$ \\
\hline Natural rate of increase in population & $1 \cdot 07(1 \cdot 04-1 \cdot 10)$ \\
\hline Urban vs. rural designation & $2 \cdot 32(1 \cdot 97-2 \cdot 78)$ \\
\hline \multicolumn{2}{|l|}{ Race/ethnicity of mother $(\%)$} \\
\hline White & $1 \cdot 01(1 \cdot 003-1 \cdot 02)$ \\
\hline Black & $0.99(0.98-1.01)$ \\
\hline Native American & $1 \cdot 00(0 \cdot 98-1 \cdot 01)$ \\
\hline Asian & $1.00(0 \cdot 99-1 \cdot 01)$ \\
\hline Hispanic & $0.99(0.98-1 \cdot 01)$ \\
\hline US born $(\%)$ & $1 \cdot 03(1 \cdot 004-1 \cdot 06)$ \\
\hline English only spoken at home (\%) & $1 \cdot 03(1 \cdot 007-1 \cdot 05)$ \\
\hline \multicolumn{2}{|l|}{ Education $(\%)$} \\
\hline \multicolumn{2}{|l|}{ Educational attainment } \\
\hline$<9$ th grade education & $0.91(0 \cdot 87-0.94)$ \\
\hline $9-12$ th grade education & $0.93(0.83-0.99)$ \\
\hline High school education & $1.00(0.95-1 \cdot 02)$ \\
\hline Graduate/professional education & $0 \cdot 98(0 \cdot 96-1 \cdot 00)$ \\
\hline \multicolumn{2}{|l|}{ Enrolment in pre-K-12th grade $(\%)$} \\
\hline White & $1 \cdot 01(1 \cdot 004-1 \cdot 017)$ \\
\hline Black & $1.01(0.99-1.02)$ \\
\hline Native American & $1 \cdot 00(0 \cdot 98-1 \cdot 02)$ \\
\hline Asian & $0.99(0.98-1 \cdot 02)$ \\
\hline Hispanic & $1 \cdot 00(0 \cdot 98-1 \cdot 01)$ \\
\hline Out-of-home daycare per 1000 in child population & $0.97(0.94-0.99)$ \\
\hline \multicolumn{2}{|l|}{ Maternal education $(\%)$} \\
\hline Low & $0.98(0.96-0.99)$ \\
\hline Medium & $0.98(0.96-0.997)$ \\
\hline High & $1 \cdot 02(1 \cdot 007-1 \cdot 03)$ \\
\hline Number of schools, per $1000(\%)$ & $0.76(0.65-0.89)$ \\
\hline Elementary & $0.43(0 \cdot 23-0 \cdot 80)$ \\
\hline Middle & $0.63(0.48-0.83)$ \\
\hline High & $0 \cdot 31(0 \cdot 15-0 \cdot 60)$ \\
\hline \multicolumn{2}{|l|}{ Vaccination status (\%) } \\
\hline 4+ DTaP & $0.99(0.98-0.996)$ \\
\hline $1+$ varicella vaccine & $0.97(0.95-0.99)$ \\
\hline Completed vaccine series & $1.00(0.99-1 \cdot 00)$ \\
\hline \multicolumn{2}{|l|}{ Socioeconomic } \\
\hline Median income & $1.00002(1.00001-1.00003)$ \\
\hline Proportion in labour force & $1 \cdot 06(1 \cdot 04-1 \cdot 10)$ \\
\hline Unemployment & $1 \cdot 04(1 \cdot 04-1 \cdot 10)$ \\
\hline Uninsured & $0.93(0.86-0.96)$ \\
\hline Single-parent households & $0.98(0.95-0.997)$ \\
\hline Average household size & $2 \cdot 62(1 \cdot 60-3 \cdot 87)$ \\
\hline Asthma hospitalizations & $0.99(0.96-1 \cdot 01)$ \\
\hline
\end{tabular}


Table 2 (cont.)

\begin{tabular}{ll}
\hline \hline Indicator & RR $(99 \cdot 9 \%$ CrI)* \\
\hline Health (\%) & \\
Pre-term births & $1 \cdot 00(0 \cdot 95-1 \cdot 05)$ \\
Adequacy of prenatal care & $1 \cdot 01(0 \cdot 99-1 \cdot 02)$ \\
Teen birth rates & $1 \cdot 00(0 \cdot 99-1 \cdot 01)$ \\
Births to unmarried mothers & $0 \cdot 99(0 \cdot 96-1 \cdot 00)$ \\
Enrolment in family-medical assistance programmes & $0 \cdot 95(0 \cdot 75-1 \cdot 10)$ \\
Enrolment in medical assistance programmes & $0 \cdot 96(0 \cdot 92-0 \cdot 99)$ \\
Adult obesity & $1 \cdot 01(0 \cdot 99-1 \cdot 03)$ \\
Childhood obesity & \\
$\quad$ Underweight & $1 \cdot 07(0 \cdot 98-1 \cdot 22)$ \\
Normal weight & $1 \cdot 02(1 \cdot 003-1 \cdot 07)$ \\
Overweight & $0 \cdot 97(0 \cdot 90-1 \cdot 01)$ \\
Obese & $0 \cdot 99(0 \cdot 92-1 \cdot 07)$ \\
Very obese & $0 \cdot 96(0 \cdot 86-1 \cdot 00)$ \\
Family medicine physicians per 100000 population & $0 \cdot 01(0 \cdot 001-0 \cdot 15)$ \\
Paediatricians per 100000 population & $0 \cdot 05(0 \cdot 003-10 \cdot 09)$ \\
\hline \hline
\end{tabular}

RR, Rate ratio; CrI, credible interval.

* Credible intervals not including 1 were considered statistically significant

$\dagger$ To two decimal places, except where statistical significance is shown.

Table 3. Multivariable regression analysis of the relationship between demographics, social indicators and pertussis incidence rate

\begin{tabular}{|c|c|}
\hline Indicator & $\operatorname{RR}(99.9 \% \mathrm{CrI})^{*}$ \\
\hline \multicolumn{2}{|l|}{ Age (\%) } \\
\hline 0-4 years & $1 \cdot 01(0 \cdot 78-1 \cdot 30)$ \\
\hline 5-9 years & $0.92(0 \cdot 67-1 \cdot 22)$ \\
\hline $10-19$ years & $0 \cdot 90(0 \cdot 78-1 \cdot 03)$ \\
\hline \multicolumn{2}{|l|}{ Race/ethnicity (\%) } \\
\hline White & $0.92(0.68-1 \cdot 36)$ \\
\hline Black & $0.96(0.67-1.56)$ \\
\hline Native American & $0.93(0.65-1.39)$ \\
\hline Asian & $0.90(0.63-1 \cdot 28)$ \\
\hline Hispanic & $1 \cdot 05(0 \cdot 97-1 \cdot 11)$ \\
\hline \multicolumn{2}{|l|}{ Demographics } \\
\hline Urban vs. rural & $1 \cdot 79(1 \cdot 43-2 \cdot 31)$ \\
\hline Average household size & $4 \cdot 75(1 \cdot 10-23 \cdot 97)$ \\
\hline Maternal education: medium & $1 \cdot 01(0 \cdot 97-1 \cdot 06)$ \\
\hline Maternal education: high & $1.02(0.98-1.07)$ \\
\hline $4+\mathrm{DTaP}$ & $0.97(0.96-0.99)$ \\
\hline Uninsured & $0 \cdot 96(0 \cdot 86-1 \cdot 08)$ \\
\hline Family medicine physicians & $0 \cdot 06(0 \cdot 00-1 \cdot 87)$ \\
\hline Paediatricians & $0 \cdot 05(0 \cdot 00-27 \cdot 33)$ \\
\hline
\end{tabular}

RR, Rate ratio; CrI, credible interval.

* Credible intervals not including 1 were considered statistically significant.

likelihood of transmission in their communities [7, 8]. Interestingly, our univariate analysis revealed a statistically significant association between a decrease in the pertussis incidence rate with an increase in density of family physicians, but not with paediatricians, even though point estimates were similar. The reason for this difference is partially due to rural counties who have no paediatrician indicated in the data whereas every county has at least one family physician. The difference in provider-type density by county is noteworthy, as vaccination rates for family physicians have been shown to be significantly lower (45-88\%) than for paediatricians $(85-99 \%)[29,30]$. Studies have attributed this to less family physician knowledge regarding vaccination recommendations and their concerns about vaccine safety, among other reasons [29, 30]. In the multivariable analysis, county family physician and paediatrician density were no longer significantly associated with pertussis incidence rate, although the rate ratios were similar and indicated a trend towards reduced rates of pertussis in counties with a higher density of either physician.

Our univariate analysis found a possible association between low and medium maternal education and a decrease in the pertussis incidence rate, but paradoxically high maternal education was associated with an increase in pertussis incidence rate. The association with high maternal education and an increase in pertussis incidence rate at the county level is consistent with other studies that have demonstrated an association between high maternal education with non-vaccination [31], although the univariate association is likely to be confounded by the urban/rural classification of a county. This may also be due to increased uncertainty about the benefits of immunization in more educated parents [32], or possible 
decreased reporting of providers in these areas to immunization registries [31].

Under-vaccination has been associated with low maternal education [31], and lack of vaccine uptake has been linked to low socioeconomic status, country of origin, and single parenthood, among others [23, 31]. While there is substantial literature documenting poorer health indices in minority and immigrant families [33], and socioeconomic and racial disparities in vaccination uptake [34], we did not find any of these to be associated with pertussis incidence rate in Minnesota in our multivariable analysis. However, this may be due to the fact that minority populations are small in Minnesota and any association may be attenuated at the county level due to the large prevalence of whites.

Urbanization, household size and crowding have also been shown to be associated with similarly transmitted infections such as measles [35], as well as a greater risk of acquiring other respiratory tract infections such as tuberculosis and respiratory syncytial virus [36, 37]. Household size has been recognized as a determinant of health given that the household environment can play an important role in the transmission of respiratory pathogens, and that the collective behaviours of household members can affect transmission at an individual level [38]. Hence, household size as well as household age composition and how they vary in different counties may be important to consider when targeting specific counties for intervention [39].

Some of the limitations of this study are due to the nature of ecological analyses, which in general can describe associations of disease occurrence at an aggregate level such as the county level used in this analysis. These associations, however, may not be present at the individual level. There could also be variation in the completeness and representativeness of the county-level data used in this analysis, even though we tried to minimize this by using state- and federal-level data from surveys that have been shown to have high coverage and completion rates. As the goal of this study was to provide a statewide analysis of potential ecological factors associated with pertussis disease, we did not explore predictive values of identified factors, which would be the next step. Our data did not include age breakdown of pertussis cases, hence we were unable to examine in detail the role of age including impact of having more infants in a given county. We were also unable to examine parental vaccine refusal due to the limited availability of these data. Our use of varicella vaccination as a proxy for vaccine exemption was based on other published literature [24]; but, this approach could potentially overestimate how many children did not receive DTaP. However, immunization uptake for all four doses of DTaP varied widely between counties, suggesting that other factors besides parental refusal may play a role in pertussis rates. Our use of the SGLMM model does not address the problem of multicollinearity that arises from strong correlation between predictors. In particular, although the model alleviates multicollinearity between the fixed-effects predictors and the random effects, the fixed-effects predictors may exhibit multicollinearity on their own. Another limitation of this analysis is that census data for some variables at the county level were for a 5-year span, which limited our ability to compare different epidemics within a 5 -year period, and also may not adequately account for changes in minor and major outbreaks, and sporadic cases identified in the intervening period. Further, the use of data from different sources, such as we have done in this analysis, is a limitation since there may be differences in the methods used, population studied and completeness of reporting. Finally, increasing awareness of pertussis leading to changes in testing patterns was also not accounted for in this analysis.

\section{CONCLUSION}

Ecological analyses can be used to identify factors that are associated with geographically varying incidence rates of pertussis to inform public health interventions. This analysis confirms the need to maintain high vaccine coverage and completion of the pertussis vaccine series, and highlights factors to consider, such as dense populations on both a large (cities/urban areas) and small (large families/day cares/schools) scale, when targeting counties for intensified surveillance and interventions.

\section{ACKNOWLEDGEMENTS}

We thank Joe Koopmeiners, Eleena Iissaka, Andrew Nicklawsky and Michael O'Connell for assistance with statistical analysis. Research reported in this publication was supported by the National Center for Advancing Translational Sciences of the National Institutes of Health Award Number UL1TR 000114.

Research reported in this publication was supported by the National Center for Advancing Translational Sciences of the National Institutes of Health Award Number UL1TR 000114.

\section{DECLARATION OF INTEREST}

None. 


\section{REFERENCES}

1. Centers for Disease Control and Prevention. Updated recommendations for use of tetanus toxoid, reduced diphtheria toxoid, and acellular pertussis (Tdap) vaccine in adults aged 65 years and older-Advisory Committee on Immunization Practices (ACIP), 2012. Morbidity and Mortality Weekly Report 2012; 61: 468-470.

2. Rohani P, Drake JM. The decline and resurgence of pertussis in the US. Epidemics 2011; 3: 183-188.

3. Centers for Disease Control and Prevention. Pertussis (whooping cough). 2012 (http://www.cdc.gov/pertussis/ outbreaks/about.html). Accessed 5 November 2014.

4. MDH. Pertussis (whooping cough). 2012 (http://www. health.state.mn.us/divs/idepc/diseases/pertussis/index.html). Accessed 5 November 2014.

5. Jackson DW, Rohani P. Perplexities of pertussis: recent global epidemiological trends and their potential causes. Epidemiology and Infection 2014; 142: 672-684.

6. Smith PJ, Chu SY, Barker LE. Children who have received no vaccines: who are they and where do they live? Pediatrics 2004; 114: 187-195.

7. Atwell JE, et al. Nonmedical vaccine exemptions and pertussis in California, 2010. Pediatrics 2013; 132: 624-630.

8. Glanz JM, et al. Parental refusal of pertussis vaccination is associated with an increased risk of pertussis infection in children. Pediatrics 2009; 123: 1446-1451.

9. Koepke R, et al. Estimating the effectiveness of tetanus-diphtheria-acellular pertussis vaccine (Tdap) for preventing pertussis: evidence of rapidly waning immunity and difference in effectiveness by Tdap brand. Journal of Infectious Diseases 2014; 210: 942-953.

10. Witt MA, Katz PH, Witt DJ. Unexpectedly limited durability of immunity following acellular pertussis vaccination in preadolescents in a North American outbreak. Clinical Infectious Diseases 2012; 54: 17301735.

11. Healy CM, Rench MA, Baker CJ. Implementation of cocooning against pertussis in a high-risk population. Clinical Infectious Diseases 2011; 52: 157-162.

12. Healy CM, et al. Evaluation of the impact of a pertussis cocooning program on infant pertussis infection. Pediatric Infectious Disease Journal 2015; 34: 22-26.

13. Walter EB, et al. Cocooning infants: Tdap immunization for new parents in the pediatric office. Academic Pediatrics 2009; 9: 344-347.

14. Castagnini LA, et al. Impact of maternal postpartum tetanus and diphtheria toxoids and acellular pertussis immunization on infant pertussis infection. Clinical Infectious Diseases 2012; 54: 78-84.

15. Healy CM, Rench MA, Baker CJ. Importance of timing of maternal combined tetanus, diphtheria, and acellular pertussis (Tdap) immunization and protection of young infants. Clinical Infectious Diseases 2013; 56: 539-544.

16. Tiensin T, et al. Ecologic risk factor investigation of clusters of avian influenza A (H5N1) virus infection in Thailand. Journal of Infectious Diseases 2009; 199: 1735-1743.
17. Wolf ER, et al. Impact of a pertussis epidemic on infant vaccination in Washington state. Pediatrics 2014; 134: 456-464.

18. Duffy E, Shea K. Effect of county-level pertussis vaccine coverage on county-level pertussis incidence rates in California during the 2010 pertussis epidemic. Poster, ID Week. San Diego, CA, 2012.

19. US Census Bureau (http://factfinder2.census.gov/faces/ nav/jsf/pages/index.xhtml). Accessed 22 April 2014.

20. Minnesota Department of Health (http://www.health. state.mn.us/pertussis). Accessed 22 April 2014.

21. Minnesota Geospatial Information Office (http://www. mngeo.state.mn.us/chouse/metalong.html\#admin). Accessed 5 November 2014

22. Ingram DD, Franco SJ. NCHS urban-rural classification scheme for counties. Vital Health Statistics 2012; 2.

23. Smith LA, et al. Rethinking race/ethnicity, income, and childhood asthma: racial/ethnic disparities concentrated among the very poor. Public Health Reports 2005; 120: 109-116.

24. Salmon DA, Siegel AW. Religious and philosophical exemptions from vaccination requirements and lessons learned from conscientious objectors from conscription. Public Health Reports 2001; 116: 289-295.

25. Hegde V, Dhurandhar NV. Microbes and obesityinterrelationship between infection, adipose tissue and the immune system. Clinical Microbiology and Infection 2013; 19: 314-320.

26. Hughes J, Haran M. Dimension reduction and alleviation of confounding for spatial generalized linear mixed models. Journal of the Royal Statistical Society, Series B 2013; 75: 139-159.

27. Clayton DG, Bernardinelli L, Montomoli C. Spatial correlation in ecological analysis. International Journal of Epidemiology 1993; 22: 1193-1202.

28. Hughes J. ngspatial: a package for fitting the centered autologistic and sparse spatial generalized linear mixed models for areal data. 2014. (http://www.biostat.umn.edu/ johnh/pdf/ngspatial.pdf). Accessed 29 October 2014

29. Daley MF, et al. Human papillomavirus vaccination practices: a survey of US physicians 18 months after licensure. Pediatrics 2010; 126: 425-433.

30. Kempe A, et al. Adoption of rotavirus vaccination by pediatricians and family medicine physicians in the United States. Pediatrics 2009; 124: e809-816.

31. Hull BP, McIntyre PB, Sayer GP. Factors associated with low uptake of measles and pertussis vaccines - an ecologic study based on the Australian Childhood Immunisation Register. Australian and New Zealand Journal of Public Health 2001; 25: 405-410.

32. Forrest JM, Burgess MA, McIntyre PB. Factors influencing vaccination uptake. Workshop report. Current Australian research on the behavioural, social and demographic factors influencing immunisation, Royal Alexandra Hospital for Children, Sydney, March 1998. Communicable diseases intelligence 2000; 24: 51-53.

33. Healy CM, et al. Pertussis serostatus among neonates born to Hispanic women. Clinical Infectious Diseases 2006; 42: 1439-1442. 
34. Dempsey A, et al. Worsening disparities in HPV vaccine utilization among 19-26 year old women. Vaccine 2011; 29: 528-534.

35. Hersh BS, et al. The geographic distribution of measles in the United States, 1980 through 1989. Journal of the American Medical Association 1992; 267: 19361941.

36. Bockova $\mathbf{J}$, et al. Respiratory syncytial virus infection in Navajo and White Mountain Apache children. Pediatrics 2002; 110: e20.
37. Wingfield T, et al. The seasonality of tuberculosis, sunlight, vitamin D, and household crowding. Journal of Infectious Diseases 2014; 210: 774-783.

38. Delabre RM, et al. Risk factors of pandemic influenza A/ $\mathrm{H} 1 \mathrm{~N} 1$ in a prospective household cohort in the general population: results from the CoPanFlu-France cohort. Influenza and Other Respiratory Viruses 2015; 9: 43-50.

39. Laskowski M, et al. The impact of demographic variable on disease spread: influenza in remote communities. Nature 2011; 1: 1-7.

APPENDIX. Sources for pertussis variables used in the analysis

\begin{tabular}{|c|c|}
\hline Data table and corresponding year(s) of collection & Source \\
\hline 1. Age and sex-specific population counts by county, 2011 & MDH [20] \\
\hline 2. Race and ethnicity by county, 2011 & MDH [20] \\
\hline 3. Children aged $<5$ years, children $0-19$ years, females $15-44$ years, 2011 & MDH [20] \\
\hline 4. Population aged $\geqslant 65$ years, 2011 & MDH [20] \\
\hline 5. Population density, 2011 & MDH [20] \\
\hline 6. Selected socioeconomic statistics, 2007-2011 & MDH [20] \\
\hline $\begin{array}{l}\text { 7. Minnesota Care, Minnesota Family Investment Programme-Medical Assistance, General } \\
\text { Assistance Medical Care Average monthly enrolment, } 2011\end{array}$ & MDH [20] \\
\hline 8. Average monthly enrollment in medical assistance, 2011 & MDH [20] \\
\hline $\begin{array}{l}\text { 9. Pre-K to 12th grade school enrolment by race and ethnicity, 2011-2012 school year, } 1 \text { October } \\
2011\end{array}$ & MDH [20] \\
\hline 10. Children in out-of-home daycare per 1000 in the child population (0-17 years), 2011 & MDH [20] \\
\hline 11. Selected birth rates, 2011 & MDH [20] \\
\hline 12. Prematurity and low birthweight of singleton births in Minnesota, 2011 & MDH [20] \\
\hline 13. Prenatal care, 2011 & MDH [20] \\
\hline 14. Teen pregnancy and birth rates, 2009-2011 & MDH [20] \\
\hline 15. Sociodemographic factors related to birth outcomes, 2011 & MDH [20] \\
\hline 16. Race and ethnicity of mother, 2011 & MDH [20] \\
\hline $\begin{array}{l}\text { 17. Percent of children aged 24-35 months up-to-date for individual vaccines and a series of these } \\
\text { vaccines, data August } 2011\end{array}$ & MDH [20] \\
\hline 18. Asthma hospitalizations: age-adjusted rates per 10000, 2008-2010 & MDH [20] \\
\hline $\begin{array}{l}\text { 19. County-level estimates of leisure time physical inactivity, diabetes prevalence and obesity in } \\
\text { adults aged } \geqslant 20 \text { years, } 2009\end{array}$ & MDH [20] \\
\hline $\begin{array}{l}\text { 20. Weight status in WIC children aged } 2-5 \text { years by county of residence, } 2012 \text { MN WIC } \\
\text { information system }\end{array}$ & MDH [20] \\
\hline $\begin{array}{l}\text { 21. Uninsurance rates for population aged }<65 \text { years from Census Small Area Health Insurance } \\
\text { Estimates, } 2010\end{array}$ & MDH [20] \\
\hline 22. Number of physicians (family physicians and paediatricians) by county, 2012 & $\begin{array}{l}\text { MBMP (M. Chu, written } \\
\text { communication) }\end{array}$ \\
\hline 23. County designation of rural vs. urban, January 2012 & NCHS [22] \\
\hline 24. Schools in county, elementary vs. middle vs. high schools, 2012 & MGIO [21] \\
\hline 25. Average household size, 5-year data & US Census [19] \\
\hline 26. Educational attainment, 5-year data & US Census [19] \\
\hline 27. US born $v s$. foreign born, 5-year data & US Census [19] \\
\hline 28. Language spoken at home, 5-year data & US Census [19] \\
\hline 29. Median income, 5-year data & US Census [19] \\
\hline 30. Proportion in labour force $v s$. unemployed, 5-year data & US Census [19] \\
\hline
\end{tabular}

MDH, Minnesota Department of Health; MGIO, Minnesota Geospatial Information Office; MBMP, Minnesota Board of Medical Practice; NCHS, National Center for Health Statistics; WIC, Women, Infants and Children. 